\title{
EL PRINCIPIO DE CAPACIDAD ECONÓMICA EN LA JURISPRUDENCIA TRIBUTARIA COMPARADA DE Chile y Españ *
}

["The Principle of Economic Capacity in the Comparative Tax Jurisprudence of Chile and Spain"]

\author{
José Antonio Fernández Amor** \\ Universidad Autónoma de Barcelona, España \\ Patricio Masbernat ${ }^{* * *}$ \\ Universidad de Talca, Chile
}

\begin{abstract}
Resumen
El presente trabajo busca identificar las concepciones que la jurisprudencia constitucional chilena y española tienen en relación al principio de capacidad económica como criterio jurídico de distribución de las cargas tributarias. Por otro lado, intenta determinar a su respecto las semejanzas que se presentan en ambos sistemas jurídicos. La conclusión es que, no obstante las diferentes inspiraciones de los constituyentes en España y Chile en el ámbito tributario, se puede apreciar una convergencia en la comprensión de este principio material de la tributación denominado capacidad económica.
\end{abstract}

\section{Palabras Clave}

Tributación; principios tributarios; igualdad tributaria; capacidad económica; jurisprudencia constitucional.
Abstract

This paper seeks to identify the conceptions that the Chilean and Spanish Constitutional Courts have in relation to the principle of hability to pay like legal criterion of distribution of the tax charge distribution. On the other hand, it tries to determine the similarities that appear in both legal systems with respect to that principle. The conclusion is that, despite the different inspirations from the Constitution in Spain and Chile in the tributary scope, it's possible to appreciate a convergence in the understanding of this material principle of taxation denominated economic capacity.

\section{KEYWORDS}

Taxation; Tax principles; tax equality; capacity to pay; constitutional decisions.

[RECIBIDo el 20 de septiembre y ACEPTADo el 14 de octubre de 2011].

* Este artículo ha sido elaborado en el marco del proyecto FONDECYT N 11100190 , denominado "Construcción de una dogmática de los principios materiales de la tri- 


\section{INTRODUCCIÓN}

La actual crisis financiera mundial vuelve a poner de manifiesto que las economías de los diferentes Estados están interconectadas no sólo a efectos de crecimiento, sino también de recesión. No es un fenómeno nuevo ya que se está analizando desde que se comenzó a debatir la globalización o mundialización de las relaciones económicas en el pasado siglo (por ejemplo, con el crack de 1929, las crisis del petróleo, etc.). Las vicisitudes que pueden sucederse durante el desarrollo económico de un Estado se trasladan rápidamente a otros Estados afectándoles a su propia actividad y progreso. Es un hecho que los Estados no son compartimentos estancos o herméticos y que, en los últimos tiempos sobre todo, se han ido entrelazando sus sistemas económicos. Esta conectividad o interdependencia hace que, en el campo económico, tiendan a asemejarse unos a otros, participando de características similares. Ejemplos significativos bien podrían ser la caída del sistema económico comunista en la antigua URSS, la adaptación del sistema económico de la República Popular China al sistema capitalista o la adopción de fórmulas propias del Estado liberal con la reducción de la actividad del sector público en Estados de la Unión Europea a través del retroceso en el volumen de gasto.

Uno de los elementos que tiene una estrecha relación con la economía de un Estado es su sistema tributario. A través de él incide en su economía y a través de él obtiene parte de los recursos que requiere para realizar su actividad. Es la seña de identidad del Estado que se trate, en tanto que es producto del ejercicio del poder más íntimamente ligado a su propia esencia: el poder tributario. Es una de las manifestaciones

butación en Chile, a la luz del Derecho Comparado", Fondo Nacional de Desarrollo Científico y Tecnológico, Conicyt, Ministerio de Educación, Gobierno de Chile. En dicho proyecto el profesor Masbernat actúa como investigador responsable y el profesor Fernández como investigador consultor extranjero.

${ }^{* *}$ Doctor en Derecho por Universidad Autónoma de Barcelona; profesor de Derecho financiero y tributario; Investigador principal del Grupo Iberoamericano de Estudios Jurídicos de la Empresa, Unidad de Derecho Financiero y Tributario, Universidad Autónoma de Barcelona; Correo electrónico: joseantonio.fernandez@uab.cat.

*** Abogado; licenciado en Derecho por la Pontificia Universidad Católica de Chile; magíster en Derecho por la Universidad de Chile; doctor en Derecho por la Universidad Complutense de Madrid; profesor de la Universidad de Talca; investigador principal del Grupo Iberoamericano de Estudios Jurídicos de la Empresa; Correo electrónico: derechotributario@utalca.cl. 
que, junto a la seguridad o las relaciones internacionales, lo caracteriza e individualiza ${ }^{1}$.

No obstante, de forma paulatina y quizá no premeditada por los titulares de los poderes tributarios, los sistemas se van acercando en sus características forzados por la competitividad entre ellos. La carga fiscal que ha de asumir un posible inversionista se convierte en un elemento que puede disuadirle o no de instalarse en un Estado. Con el objetivo de ser más atractivos a estos inversionistas, se equiparan los tipos impositivos o las condiciones fiscales a las que poseen otros Estados vecinos.

Estas líneas tienen como fin exponer algunas reflexiones en torno a esta idea, sobre ese acercamiento entre los sistemas tributarios aunque no en relación con los tipos impositivos o el gravamen que ha de soportar una persona contribuyente. El objeto de interés es más bien un aspecto fundamental como es el principio que rige el reparto de la carga tributaria entre ciudadanos. Se trabaja con la hipótesis de que dos sistemas tributarios diferentes como es el chileno y el español, que presentan diferencias en los principios materiales que los fundamentan, se han acercado a la hora de aplicar el principio que rige el deber de contribuir a los gastos públicos².

La exposición que sigue se desarrolla en tres partes. El primer apartado consiste en un acercamiento a aspectos básicos de los principios constitucionales que el ordenamiento chileno y español prevén para el reparto de las cargas tributarias. En un segundo apartado, se ha de exponer qué contenido han dado los tribunales de ambos Estados al principio de reparto de la carga tributaria para, finalmente, en un tercer apartado aportar algunas conclusiones en torno a la hipótesis que motiva estas líneas.

${ }^{1}$ La realidad fiscal de la UE es prueba de esta afirmación. En su seno se han conseguido cotas de integración entre los Estados miembros en áreas económicas. Pero en materia de tributos conservan sus potestades y manifiestan reticencias a la hora de ceder esta parcela de soberanía a la organización supranacional. Se ha alcanzado una armonización -que no uniformidad- en materia del Impuesto sobre el valor añadido (IVA) y otros tributos indirectos por su directa vinculación con el tráfico económico. No se ha alcanzado un nivel semejante en materia de tributación directa en la que los Estados conservan su capacidad tal y como lo muestra el hecho de que existan tantos Impuestos sobre la renta de las personas físicas o jurídicas como Estados miembros.

${ }^{2}$ El motivo de contrastar este aspecto del ordenamiento jurídico de los dos Estados es la distancia que existe entre ambos en cuanto a su concepción del Estado como institución que, sin ninguna duda, condiciona el reparto de la carga tributaria. De forma sumaria, la República de Chile parte de una concepción liberal de la institución mientras que el Reino de España de una idea de Estado social que se consagra en el artículo 1 CPol.Esp. 


\section{CONTRASTE DE LOS PRINCIPIOS}

\section{QUE RIGEN LA DISTRIBUCIÓN DE LAS CARGAS PÚBLICAS} EN LAS CONSTITUCIONES CHILENA Y ESPAÑOLA

\section{El principio de igualdad como criterio de reparto en la "Constitución" chilena.}

De acuerdo con lo establecido en el artículo 19 No $20 \mathrm{CPol}$. (texto refundido de 17 de septiembre de 2005): "La Constitución asegura a todas las personas: [...]. 20. La igual repartición de los tributos en proporción a las rentas o en la progresión oforma que fije la ley. En ningún caso la Ley podrá establecer tributos manifiestamente desproporcionados o injustos. Los tributos que se recauden, cualquiera que sea su naturaleza, ingresarán al patrimonio de la Nación y no podrán estar afectos a un destino determinado. Sin embargo, la ley podrá autorizar que determinados tributos puedan estar afectados a fines propios de la defensa nacional. Asimismo, podrá autorizar que los que gravan actividades o bienes que tengan una clara identificación regionalo local puedan ser aplicados, dentro de los marcos que la misma ley señale, por las autoridades regionales o comunales para el financiamiento de obras de desarrollo".

Del texto citado se pueden extraer diversas conclusiones. En primer término, el legislador constitucional chileno prevé diversos principios a los que ha de adaptarse el legislador a la hora de establecer tributos. Por una parte, se puede identificar un principio de igualdad frente a la repartición de los tributos. Por otro lado, desde la literalidad de la norma, se podría sostener la consagración de principios como el de proporcionalidad o el de progresividad, que vendrían a dar contenido a ese principio de legalidad ${ }^{3}$. Además se añade al conjunto la mención a un principio de justicia cuyo contenido es que el tributo que se vaya a establecer no puede ser desproporcionado o injusto. Cierra el artículo - aunque es una cuestión que queda fuera del interés de este trabajo- una previsión en torno al principio de no afectación de los ingresos

\footnotetext{
${ }^{3}$ No obstante reconocemos que, desde una perspectiva del actual desarrollo dogmático chileno, que debe ser superado, no pasarían de ser criterios de configuración de tipos impositivos. En efecto, así fue expresado por el Tribunal Constitucional en la sentencia rol No 280/1998, de 20 de octubre, que se respalda en lo decidido en la sentencia rol $N^{\circ} 219 / 1995$, de 30 de julio, consid. $8^{\circ}$, que destaca lo difícil que es determinar si el tipo impositivo de un tributo es desproporcionado o injusto, debido a que "existen múltiples factores, todos de hecho, que inciden en su calificación”, mencionándolos (consid. 18 ${ }^{\circ}$ ). El Tribunal también se apoyó en su sentencia rol $N^{\circ} 219 / 1995$, consid. $9^{\circ}$, en torno a la idea de los límites de la tributación (la libertad de empresa y derecho a la propiedad) para finalmente estimar proporcional el tipo de gravamen propuesto en el proyecto de ley cuestionado.
} 
tributarios salvo que la ley establezca otra cosa haciendo una alusión a la distribución de la recaudación entre entidades regionales y locales ${ }^{4}$.

En segundo término, se ha de destacar cómo el legislador chileno reparte las cargas públicas que implican los tributos. Podría sostenerse que el constituyente tiene la previsión de un principio de igualdad material en tanto que asocia expresamente la igualdad con la proporcionalidad y la progresividad. Pero no es un tema que deja cerrado o abocado a sólo estos principios sino que abre la posibilidad que sea la propia ley la que establezca el criterio de reparto.

El principio de igualdad se garantiza, por tanto, tanto con el reparto proporcional de la carga tributaria, como por el reparto progresivo de la misma y, finalmente, el legislador puede optar por otros medios como podría ser un principio de beneficio. En consecuencia, el legislador chileno puede formar un sistema tributario compuesto por tributos de diverso tipo que pueden caracterizarse por diferentes métodos de reparto de la carga que suponen. Ello podría disminuir en Chile la fuerza del principio de capacidad económica, al constituir éste sólo un criterio más de reparto de la carga impositiva.

La tercera apreciación que se puede realizar sobre el precepto, por lo que a principios de la tributación se refiere, es que el legislador constitucional establece un límite al poder tributario. No pueden ser establecidos tributos manifiestamente desproporcionados o injustos. Entiende el constituyente que un tributo, si puede llegar a ser desproporcionado, ha de ser expulsado del sistema ${ }^{5}$. Del propio texto del artículo se deduce que este defecto habrá de darse cuando el gravamen no es proporcional a la renta gravada ${ }^{6}$.

El legislador añade que los tributos no pueden ser injustos. Establece esta previsión detrás de la conjunción 'o' por lo que cabe entender que hay dos posibilidades de que se dé un defecto en el tributo establecido. Bien puede ser desproporcionado a la renta o bien puede ser injusto. Dado lo indeterminado de este último término parece que, de forma paralela al carácter abierto de

${ }^{4}$ Un estudio comprensivo acerca de la doctrina tributaria chilena relativa a los principios materiales de la tributación, se encuentra en: MAsbernat, Patricio, Un análisis crítico de la doctrina relativa a los principios materiales de la tributación en Chile, en VV. AA, Problemas actuales de Derecho tributario comparado. Una perspectiva de Iberoamérica (Santiago, Editorial Librotecnia, en prensa).

${ }^{5}$ Debe tenerse en cuenta que en la historia del establecimiento de la disposición constitucional, el único registro relativo a la idea del tributo desproporcionado la vincula con la protección de la propiedad privada. Nótese que no se refiere a proporción como oposición o alternativa de progresión, ya que se permite otras opciones frente a los tipos proporcionales (progresivos, fundados en el beneficio, etc.).

${ }^{6}$ Conforme la doctrina chilena ha sostenido, esta proporcionalidad se mide como un criterio de razonabilidad: no violar la propiedad, no ser confiscatorio. Al respecto, véase: MASBERnAT, cit. (n. 4). 
la fórmula de reparto, el legislador constitucional también deja abierta las posibilidades de estimar si un tributo es o no injusto ${ }^{7}$.

Sintetizando, el legislador constitucional chileno establece una serie de referentes para el reparto de las cargas tributarias si bien, en última instancia, confía en el criterio que pueda seguir el legislador ordinario ${ }^{8}$. Establece un límite que parece más preciso en tanto que no ha de ser desproporcionado el gravamen y otro límite de carácter más abierto en tanto que el tributo no habrá de ser injusto?.

\section{El principio de capacidad económica como criterio de reparto en la} "Constitución" española.

El artículo 31.1 CPol.Esp. establece que: "Todos contribuirán al sostenimiento de los gastos públicos de acuerdo con su capacidad económica mediante un sistema tributario justo inspirado en los principios de igualdad y progresividad que, en ningún caso, tendrá alcance confiscatorio".

Mediante este precepto se han establecido referentes para el legislador ordinario de cómo ha de ejercer su poder de establecimiento de tributos. Se

${ }^{7}$ A nuestro parecer, es plausible una postura científica que persiga una construcción dogmática de los principios del Derecho tributario más equiparable a las instituciones del Derecho comparado. Con todo, debe considerarse el estado de la cuestión. En la doctrina chilena no existe consenso acerca del contenido de esta categoría porque no se ha hecho una construcción dogmática suficiente. La doctrina más citada y la jurisprudencia de la Corte Suprema y del Tribunal Constitucional sostienen que la prohibición de establecer tributos injustos y desproporcionados sólo tiene por objeto prohibir los tributos confiscatorios. Cfr. Masbernat, cit. (n. 4).

${ }^{8}$ Debe ponerse de manifiesto que el problema ha sido que en Chile la doctrina y la jurisprudencia coinciden en interpretar que el legislador tiene una muy amplia potestad tributaria, no sujeta a principios adecuadamente configurados que permitan adecuar su labor al sistema juridico. De este modo, en el estado actual de la doctrina, se estima como suficiente para aprobar el test de constitucionalidad que el tributo o un elemento de él se consagre por ley, sin más. En efecto, el Tribunal Constitucional sostiene que el legislador goza de un amplio margen de libertad (usa esta palabra, v.g., en sentencia roles $\mathrm{N}^{\circ} 1399 / 1469$, acumulados, de 4 de noviembre de 2010, consid. $27^{\circ}$ ) o de discrecionalidad (sentencia $\mathrm{N}^{\circ} 1452$, de 5 de agosto de 2010, considerandos $20^{\circ}$ y $21^{\circ}$ ) en el ejercicio de su potestad de configuración del sistema tributario, que le permite perseguir tanto fines recaudatorios como extra-recaudatorios, de promoción del bien común, y hacer uso de los tributos como una herramienta para lograr fines de carácter político, económico y social (destinados a motivar o desincentivar el desarrollo de una actividad, a corregir distorsiones en el mercado, estabilizar la economía, redistribuir ingresos, etc.).

${ }^{9}$ Los autores tienen presente que ambas categorías (desproporcionado e injusto) son abiertas y que la doctrina, en el momento actual, no ha logrado establecer distinciones suficientes. Por otro lado, cuando la Constitución prohíbe el tributo desproporcionado no hace referencia al tipo impositivo proporcional. Cfr. Masbernat, cit. (n. 4). 
diferencian los principios de generalidad, capacidad económica, igualdad, progresividad y no confiscatoriedad. Concurriendo todos ellos en el sistema tributario se alcanza el principio de justicia en el reparto de las cargas públicas.

El precepto establece, por un lado, expresamente un criterio de reparto de los gastos públicos cuando entiende que se ha de hacer de acuerdo con la capacidad económica de todas las personas contribuyentes. Por otro lado, la contribución se ha de hacer mediante un sistema de tributos que ha de reunir el carácter de justo al estar inspirado en los otros principios ya mencionados. Así pues, el principio de capacidad económica queda como el criterio principal en el ordenamiento español de reparto de cargas tributarias.

El principio de capacidad económica supone contribuir a los gastos públicos en función del nivel de riqueza que pueda tener el sujeto gravado. Es fácilmente deducible que la contribución será mayor o menor en función de la capacidad económica de la que pueda ser titular el sujeto gravado. Esta diferenciación admitida a la hora de contribuir a los gastos públicos determina el contenido del principio de igualdad al que también hace referencia el precepto que se comenta. La igualdad no es de carácter formal sino de carácter material en tanto que el poder tributario grava a los ciudadanos no por igual y uniformemente, sino en función del criterio señalado: capacidad económica.

Pero no parece que el legislador constitucional haya dejado, a diferencia de lo que ocurre con el caso chileno, un amplio margen al legislador ordinario para establecer la diferenciación que implica gravar de acuerdo con el principio de capacidad económica. Se establece una preferencia por el principio de progresividad frente a otros principios como puede ser el de proporcionalidad o el de beneficio aunque no por ello han de entenderse excluidos de utilización.

Se entiende, por tanto, que la justicia en el sistema tributario español vendría de la mano de los principios de capacidad económica, igualdad y progresividad necesariamente delimitándose con ello las posibilidades que tiene el legislador español pues ha de procurar que predominen en dicho sistema. Sin mayor consideración podría entenderse que, en comparación, el legislador constitucional chileno es menos estricto en tanto que deja en última instancia a la ley el establecimiento de criterios de reparto siempre que no sean desproporcionados o, insistiendo en la indeterminación, injustos. En otros términos, en el ordenamiento chileno es suficiente para superar las exigencias constitucionales con que el tributo venga establecido por ley (lo que deriva el debate de los límites al legislador hacia el alcance de esa exigencia). En cambio, la Constitución española no se conforma con este aspecto (previsto en su artículo 31.3) sino que condiciona también cómo ha de ser el sistema tributario para responder al principio de justicia que es base principal del ordenamiento jurídico (artículo 1.1 CPol.Esp). Pero la 
cuestión que se puede formular es si realmente es una conclusión correcta, es decir, si el legislador chileno ha establecido menos rigideces que el legislador español a la hora de regular los límites al ejercicio del poder tributario. Para confirmar o no esta idea se ha de realizar un repaso de pronunciamientos judiciales relativos a los principios constitucionales.

\section{DESARROLLO JURISPRUDENCIAL}

DEL PRINCIPIO DE REPARTO DE LA CARGA TRIBUTARIA

\section{Jurisprudencia chilena ${ }^{10}$.}

La Constitución Politica chilena contempla el recurso de protección de derechos fundamentales (artículo 20), de competencia de las Cortes de Apelaciones (en primera instancia) y de la Corte Suprema. Se trata de un mecanismo procesal de estructura compleja y asistemática, que mezcla tanto aspectos de legalidad, de justicia del caso (a través de la idea de arbitrariedad) y de constitucionalidad. Lo importante, para efectos de este estudio, es que abre la posibilidad de que las Cortes se pronuncien sobre cuestiones constitucionales. Por otro lado, hasta antes de la reforma constitucional de 2005, la Corte Suprema tenía competencia sobre la acción de inaplicabilidad por inconstitucionalidad (que desde ese año pasó a la competencia del Tribunal Constitucional), y en virtud de dicho mecanismo tuvo la oportunidad de pronunciarse acerca de asuntos constitucionales tributarios.

a) Corte Suprema y Cortes de Apelaciones. Recientemente, en el caso "Sociedad de Inversiones Madel Limitada contra I. Municipalidad de Providencia"11, se planteó a la Corte de Apelaciones de Santiago un supuesto en el que se interpuso un reclamo por ilegalidad contra un acto de la alcaldía. El contenido de este último era contrario a la pretensión de la contribuyente en orden a que se le considerase exento de la patente municipal (impuesto

${ }^{10}$ Figueroa VAldés, Juan, Las garantías constitucionales del contribuyente en la CPR de 1980 (Santiago, Editorial Jurídica de Chile, 1985), p. 167, sostiene que en Chile no existe jurisprudencia sobre la capacidad económica, ya que es una materia respecto de la cual se considera que queda entregada a la soberanía y prudencia del legislador (es decir, no constituye principio jurídico constitucional que pueda servir de parámetro para el control de constitucionalidad de las leyes). En lo esencial, el argumento expuesto por este autor sigue siendo reproducido por los tribunales, aunque por otro lado, los juzgadores se pronuncien de modo cada vez más extenso acerca de los fundamentos de la tributacion. Con todo, como se muestra en este trabajo, existe una evolución, aunque sea todavía limitada.

${ }^{11}$ Corte de Apelaciones de Santiago, 26 de marzo de 2011, rol N 5802-2010, reclamo de ilegalidad en ámbito municipal, "Sociedad de Inversiones Madel Limitada c. I. Municipalidad de Providencia” [cita de Base de Datos www.westlaw.cl: CL/ JUR/3541/2011, visita 17 de julio de 2011]. 
local). En definitiva, la Corte de Apelaciones desestimó el recurso deducido ante ella.

De las diferentes circunstancias que rodearon al caso, la parte demandante alegaba que se infringía los artículos $19 \mathrm{~N}^{\circ} 2$ y 20 constitucionales que reconocen la igualdad en materia tributaria, por cuanto la definición de la carga tributaria a grupos de contribuyentes en análogas circunstancia conforme a criterios tales como la capacidad económica correspondía al legislador. El argumento de la parte es que la municipalidad no es competente para negar el carácter exento de la sociedad sino que, en virtud del principio de legalidad y por el carácter amplio de los criterios de reparto de la carga tributaria, es el legislador quien ha de considerar que la entidad está sujeta a la patente municipal.

No es esta la opinión del Tribunal Constitucional cuando concluye, después de analizar el hecho imponible de la patente municipal y el objeto de la sociedad contenido en sus estatutos, que el contribuyente desarrolla actividades lucrativas, las que configuran el hecho gravado de acuerdo a la Ley de rentas municipales, con lo que el acto municipal no viola dicha norma legal ni menos normas constitucionales. De esta tesis se infiere que es la ley la que establece el hecho imponible y, por ende, la manera de repartir la carga tributaria entre los sujetos pasivos que quedarán gravados por el hecho de manifestar algún lucro o ganancia.

El tribunal defendió la existencia de un amplio margen para el establecimiento de la carga tributaria para el legislador. Los principios tales como el de igualdad quedarían resguardados con la inclusión de los contribuyente que se encuentren en "situaciones análogas" en categoría construidas por el legislador conforme "a algunos de los criterios formulados por la doctrina económica", indiferenciadamente, entre los que se encuentra tanto la capacidad contributiva, como el origen de las rentas, el beneficio del contribuyente o cualquier otro. Es decir, el criterio de capacidad económica no constituiría un concepto jurídico sino uno de carácter económico, y su uso por parte del legislador sería optativo, para el caso de que el legislador estime necesario usarlo y frente a la posibilidad igualmente válida de recurrir a cualquier otro criterio económico.

Mayor desarrollo conceptual expone unos meses antes la Corte de Apelaciones de Concepción en la sentencia que decide el caso "Gerhard Schweinitz c. Servicio de Impuestos Internos"12. El supuesto que se plantea al tribunal es

\footnotetext{
${ }^{12}$ Corte de Apelaciones de Concepción, 1 de diciembre de 2010, rol N ${ }^{\circ} 800-2010$, reclamación tributaria, "Gerhard Schweinitz Gutiérrez c. Servicio de Impuestos Internos" [cita Base de Datos www.westlaw.cl: CL/JUR/10301/2010, visita, 3 de agosto de 2011]. Un comentario extenso acerca de la sentencia del Tribunal Constitucional recaída en las normas legales de que trata esta sentencia, y de esta misma sentencia,
} 
una apelación por parte del contribuyente contra una sentencia que denegaba su pretensión consistente en la aplicación retroactiva de la norma tributaria que modificaba la calificación de sus rentas como rendimientos del trabajo dependiente. Entiende el contribuyente que antes de la modificación, el legislador dispensaba un trato desigual hacia los prácticos del puerto (oficio del apelante) al incluirlos en el régimen de trabajadores dependientes. Dada la modificación legal que incluye sus rentas en el régimen jurídico de trabajadores no dependientes, entiende que el legislador ha corregido una situación inconstitucional contraria al principio de igualdad constitucional, lo que le genera un derecho a la devolución de ingresos indebidos durante los años anteriores a la modificación en la que se le consideró trabajador dependiente a efectos fiscales.

La Corte rechazó la aplicación retroactiva en el sentido que pretendía el contribuyente, por diversos motivos, entre los que se destaca, en lo que nos interesa, que: "[...] al enjuiciar la igualdad de una determinada norma tributaria, debe tenerse presente que es de la esencia de tales normas establecer regimenes diferenciados atendiendo a las capacidades contributivas" y agrega, citando a Evans que "[...] la igualdad tributaria resulta ser una especie dentro del género igualdad ante la ley; en ésta todas las personas son iguales, en aquélla no todas son iguales ante la ley del tributo" pues "es la ley del tributo la que tiene que ser igual frente a capacidades contributivas iguales" (sentencia del Tribunal Constitucional, rol No 1399, de 4 de noviembre de 2010). Rechaza la acusación de arbitrariedad de la ley, citando un párrafo de la sentencia del mismo tribunal rol No 1399 (si bien la Corte incurrió en error, ya que el párrafo citado corresponde al voto disidente), que niega que el legislador de 1976 haya incurrido en arbitrariedad al dar a los prácticos autorizados el tratamiento de dependientes, "[...] pues la naturaleza de la actividad realizada por aquellos es sui géneris y frente a ella bien puede el legislador establecer una ficción que los asimile a la categoria de trabajadores dependientes" o a la categoría de independientes.

De las reflexiones del Tribunal, se extraen dos cuestiones en línea a lo considerado. Primero, el legislador tributario establece los criterios de reparto de la distribución de la carga tributaria y regula el estatuto de los contribuyentes de forma autónoma a cómo los puede considerar otras ramas del ordenamiento (mientras que la figura del contribuyente es cercana al trabajador no dependiente, se admite que el legislador tributario lo califique en una fictio

en: Masbernat, Patricio, Principios constitucionales tributarios en la sentencia rol $N^{o}$ 1399-09-INA y No 1469-09-INA, acumulados, del Tribunal Constitucional, de 4 de noviembre de 2010. Referencia al caso 'Gerhard Schweinitz con SII, Corte de Apelaciones de Concepción, rol 800-2010, de 1 de diciembre de 2010, en Estudios Constitucionales, 2 (Santiago, 2011, en prensa). 
iuris como dependiente ${ }^{13}$ ). No obstante, el reparto que pueda llevarse a cabo siguiendo las capacidades contributivas de cada sujeto gravado es lo que lleva a considerar que el principio de igualdad alegado por el apelante es de carácter material, enfoque de la igualdad no compartido por la Corte.

Esta sentencia se alínea con el enfoque interpretativo de la Corte Suprema presente en el caso "American Express Bank con Servicio de Impuestos Internos" 14 , en el cual desestimó un recurso de inaplicabilidad de ley tributaria por inconstitucionalidad interpuesto por vulneración del principio de igualdad fundado en el hecho de que los bancos extranjeros tributaban con base imponible y tipos de gravamen muy diferentes según si habían sido constituidos como agencia de banco extranjero o como sociedades chilenas. A juicio de la Corte, lo que la Constitución consagraba con este principio era una "igualdad relativa", la que implicaba que "todos quienes se encuentran en idénticas condiciones deben ser gravados tributariamente de la misma manera", y es a la ley a la que le cabe establecer, con efectos generales, las condiciones por las que nace la obligación tributaria. La Corte no consideró los hechos del caso. Según la sentencia, el legislador era plenamente libre, ya que "[...] bien pudo determinar la repartición proporcional y la forma del impuesto entre ese grupo de contribuyentes beneficiados con la plusvalia, sin menoscabo de la garantia constitucional", pues, constitucionalmente, el tributo se puede establecer "en proporción a las rentas o en la progresión o en la forma que fije la ley".

El caso "Servicio de Impuestos Internos con Juan Pablo Benjamín Dávila Silva" ${ }^{15}$, se origina en el cobro de impuestos sobre ingresos irregulares (derivados de accion delictiva), el contribuyente reclamó que no cabía tributar sobre ellos. La Corte Suprema se inclinó por la posición de la Administración Tributaria. El fallo consideró equivalentes la "capacidad contributiva" con el "deber legal de pagar tributos", afirmando que "el impuesto a la renta constituye uno de los elementos más completos para exteriorizar la capacidad contributiva de un sujeto" (considerando $17^{\circ}$ ).

Otra sentencia resulta útil por aportar un dato más sobre cómo se delimita el criterio de contribución a los gastos públicos. En la causa "Sociedad

${ }^{13}$ El planteamiento del Tribunal es precisamente el contrario, en aplicación del parámetro del tertium comparationis (sentencia roles No 1399/1469, acumulados, 4 de noviembre de 2010 , consid. $16^{\circ}$.

${ }^{14}$ Corte Suprema, 16 de octubre de 1996, rol N³74-96, recurso de inaplicabilidad por inconstitucionalidad, "American Express Bank con Servicio de Impuestos Internos”, en Gaceta Jurídica, 197 (1996), p. 202-207.

${ }^{15}$ Corte Suprema, 2 de septiembre de 1997, rol N³983-1996, recurso de casación en la forma, "Servicio de Impuestos Internos con Juan Pablo Benjamín Dávila Silva", consid. $17^{\circ}$. Base de datos Legal Publishing, www.legalpublishing.cl, archivo $\mathrm{N}^{\circ} 14796$ [visita de 10 de marzo de 2011]. 
Comercial Ivonne S. A.c. Tribunal Tributario de la Duodécima Región" ${ }^{16}$, la Corte Suprema trata un supuesto en que se solicita la inconstitucionalidad de una ley que aumenta el tipo impositivo del impuesto que grava el whisky alegando el carácter injusto del alza por ser desproporcionado. Concretamente, el recurrente reclama que se ha realizado una elevación de los tipos equiparable a una confiscación y expropiación sin indemnización.

El tribunal expone que la Constitución no ha concretado cuándo un tributo puede ser injusto o desproporcionado a pesar de que fue un aspecto que se llego a considerar por sus redactores. En este sentido, la ley puede establecer un tributo de acuerdo con determinados criterios que serán, en todo caso, analizados y calificados oportunamente por los Tribunales. Sobre el caso concreto la Corte Suprema estima: "Que es un principio de justicia tributaria que las cargas impositivas sean proporcionales a los ingresos y a los patrimonios de los contribuyentes y a la calidad de prescindibles e imprescindibles de los productos materia de alguna transacción gravada; ahora bien si se dicta una norma legal que establece tributos que empobrecen al contribuyente o le cercenan sus ingresos en términos confiscatorios, es indudable que la ley que asílo disponga es inconstitucional, pero ¿reviste esta naturaleza la norma que establece una tasa de $70 \%$ a la compraventa del whisky? La respuesta es obvia, no, ya que si bien es evidente que el precio del whisky se elevará en un 15\%, pues esta tasa de $70 \%$ reemplaza a una de 55\% que rigió hasta 1985, esta alza de tributo no cercena rentas, no disminuye ni confisca patrimonio, sino que hace más caro y seguramente, en un primer momento, produce una baja en las ventas".

Se deduce de estas palabras que el criterio para repartir las cargas tributarias ha de tener en cuenta un límite como es que se empobrezca al contribuyente o se le cercenen los ingresos, lo que se torna evidente cuando la carga tributaria agota la riqueza imponible sobre la que se establece ${ }^{17}$. La

${ }^{16}$ Corte Suprema, 11 de mayo de 1994, rol No 19584-1994, recurso de inaplicabilidad por inconstitucionalidad, "Sociedad Comercial Ivonne S. A. contra Tribunal Tributario de la Duodécima Región" [cita de Base de datos Westlaw Chile, www.westlaw. cl: CL/JUR/31/1994, visita 10 de agosto de 2011].

${ }^{17}$ Es posible entender esta prohibición constitucional en dos sentidos: el tributo puede ser confiscatorio si afecta de manera muy gravosa el bien sobre el que recae, con independencia de la capacidad de soportarlo por el contribuyente; o puede considerarse confiscatorio sólo en caso de que empobrezca o cercene el patrimonio del contribuyente. Creemos que el parámetro en Chile, debido a la extensa tutela del derecho de propiedad, es mucho más amplio: el impuesto desproporcionado conduce a la confiscatoriedad, aunque ella se trate de un bien en particular y no perjudique la riqueza total del contribuyente. Ello se producirá, v.g., en un impuesto territorial (impuesto sobre de bienes inmuebles) que sea demasiado alto en relación al valor de ese bien, aunque el contribuyente no vea con ello perjudicada su riqueza disponible. 
idea de la prohibición de confiscatoriedad se encuentra presente, pero no es la única extensión posible de la sentencia.

Finalmente cabe citar al caso "Compañía de Teléfonos de Chile c. Municipalidad de Villa Alemana"18, el recurrente impugna una reforma legal debido a que deja en manos de la municipalidad la configuración de los elementos básicos de la obligación tributaria; y permite al municipio determinar el tipo de gravamen entre rangos muy amplios y sin sujeción alguna a la capacidad de pago del contribuyente.

En su sentencia, la Corte Suprema sostuvo que el principio de legalidad es la garantia del principio de igualdad: "la sujeción al principio de legalidad del tributo, en cuanto configura sus elementos esenciales, constituye una garantia de la igualdad y equidad". Declaró inconstitucional la norma impugnada, porque permitía que el municipio determinara los elementos esenciales del tributo, lo que vulneraba la igualdad. La Corte, en esencia, consideró que el trato igualitario era aquel que se producía por una ley con notas de generalidad, y no mediante actos administrativos (de alcance mucho más limitado), que en materia municipal sólo tendrían una aplicación restringida al territorio comunal, por lo que en diferentes municipios dos contribuyentes con semejantes niveles de activos fijos y variables, podrían pagar diferentes cantidades de dinero por concepto de tributos ${ }^{19}$.

Sintetizando, de los pronunciamientos aquí expuestos se puede derivar que el legislador tributario puede establecer sus criterios para la distribución de los tributos pero siguiendo unas referencias esenciales. Primero, habrá de gravar manifestaciones de capacidad económica y, segundo, habrá de realizar la distribución conforme a ese criterio. Pudiera concluirse, por tanto, que la libertad de actuación que el constituyente preveía en un principio no es tal a la luz de los pronunciamientos citados. Los tribunales han marcado al legislador el camino a seguir a la hora de construir un sistema tributario que pueda ser considerado justo. En otros términos, se puede interpretar que un impuesto

${ }^{18}$ Corte Suprema, 28 de enero de 1992, rol N 16.293, recurso de inaplicabilidad por inconstitucionalidad interpuesto en contra de disposiciones de la Ley de rentas municipales, "Compañía de Teléfonos de Chile contra Municipalidad de Villa Alemana” [cita de Base de datos Microjuris www.microjuris.cl: MJCH_MJJ1522 / RDJ1522, visita de 7 de agosto 7,2010$]$.

${ }^{19}$ Sobre un caso muy semejante, el Tribunal Constitucional de Chile opinó diametralmente lo opuesto, desestimando un requerimiento de constitucionalidad de ley de carácter previo que dejaba en manos del municipio la determinación de la cuantía del impuesto municipal), porque, a su juicio, el derecho de igualdad impositiva (que implica que los tributos deben ser iguales, proporcionados y justos) no se desconocía en la reforma legal propuesta ya que sólo modificaba un límite máximo impositivo, y "de esta sola modificación no podría derivarse una desigualdad ante la ley ni menos que ésta signifique una diferencia arbitraria" (rol No 203/1994, consid. 11). 
puede ser considerado injusto si no atiende a la lógica que impone la capacidad económica pues, insistiendo en las palabras citadas, es esencia de la norma tributaria diferenciar según la capacidad económica que grava. Las sentencias citadas consideran un dato más, como es el de un límite a la contribución de acuerdo con la capacidad económica. El tributo que se trate no ha de implicar la eliminación de la riqueza sobre la que recae puesto que, de ser así, pasaría de ser un elemento de contribución a uno de confiscación.

Si bien la posición institucional del Tribunal Constitucional es diferente, es posible notar en sus pronunciamientos un acento aún mayor en el mismo sentido.

b) Tribunal Constitucional chileno. El Tribunal Constitucional de Chile ha ido, de modo progresivo, ampliando sus planteamientos acerca de cuestiones tributarias. Su sentencia rol No 203/1994, de 6 de diciembre, desestimatoria, resolvió una petición de inconstitucionalidad de la modificación introducida a la ley de impuestos locales fundada en que establecían tributos manifiestamente desproporcionados e injustos, por cuanto los alzaba cuadruplicando su límite máximo. El Tribunal hizo suyo lo sostenido por la Comisión de Constitución, Legislación, Justicia y Reglamento del Senado (sesión extraordinaria 35a , de 14 de septiembre de 1994), a fin de rechazar la presentación, afirmando que el juicio acerca de la manifiesta desproporción e injusticia de los tributos es "eminentemente valórico", y que ella "debe ser ponderado de acuerdo con la capacidad de pago del contribuyente y no en relación con el monto anterior del impuesto que se modifica" (consid. $7^{\circ}$ ). No explicita ni desarrolla el contenido de la capacidad de pago.

La sentencia del Tribunal Constitucional rol No 219/1995, de 10 de julio, desestimatoria, que resolvió un requerimiento en contra de un proyecto de ley que aumentaba los impuestos al tabaco y gasolina, afirmó que la Constitución no fijaba límites al legislador a partir del cual el impuesto se deba entender confiscatorio, y sólo debe calificarse como tal en caso de que su monto sea injustificable o irracional, lo que se produce en caso de que el abuso sea descubierto, patente, claro. Agregó que en materia de impuesto indirectos, la determinación del tipo de gravamen responde a múltiples factores, entre los que destaca "la capacidad de pago del contribuyente, la calificación del bien como de uso o consumo habitual o de carácter suntuario o prescindible o si con su imposición se impide el desarrollo de una actividad económica, factores todos que implican a juicio de este Tribunal apreciaciones eminentemente valóricas" (consid. $8^{\circ}$ ), siendo todas ellas situaciones de hecho difíciles de precisar que deben acreditarse fehacientemente para que puedan fundar una decisión de inconstitucionalidad (reproduciendo la sentencia del Tribunal Constitucional rol No 203/1994). El tribunal desestimó el recurso, por cuanto la reforma legal cuestionada sólo constituía un alza de 
un impuesto ya establecido; que no había sido previamente objetado en su constitucionalidad; $y$, en todo caso, que tampoco limitaba el ejercicio de una actividad empresarial ya que no "torna ilusorio o, al menos, estorba de manera significativa el ejercicio de dicha actividad".

En su sentencia rol No 280/1998, de 20 de octubre, este alto Tribunal desestimó un requerimiento de inconstitucionalidad en contra de un proyecto de ley que aumentaba los impuestos al tabaco y la gasolina, presentación fundada en que con dicha reforma se establecían "impuestos manifiestamente desproporcionados e injustos". A juicio del sentenciador, el legislador se encuentra sólo excepcionalmente limitado por la Constitución, y la citada prohibición constitucional sólo intenta evitar "las desproporciones o injusticias tributarias que traspasen todos los limites de lo razonable y lo prudente”, y que para ser acogido un requerimiento, la "desproporción o injusticia tiene que ser tan evidente que, cualesquiera sean los hechos, ella resulte patente y clara en la propia disposición legal' (consid. 19\%), lo que para este Tribunal no sucedía en la causa. En esta sentencia, las menciones a la capacidad económica se vierten en los considerandos $18^{\circ}$ y $19^{\circ}$, y básicamente reproducen la sentencia rol $N^{\circ}$ $219 / 1995$, afirmando que la desproporcionalidad o injusticia de la tasa del tributo es posible determinarla "mediante múltiples factores de hecho", entre ellos, "la capacidad de pago del contribuyente"; compartiendo el planteamiento de la Comisión de Constitución, Legislación y Justicia del Senado, en cuanto "la proporción o desproporción de un tributo debe ser ponderada de acuerdo a la capacidad de pago del contribuyente y no en relación con el monto anterior del impuesto que se modifica".

La sentencia rol No 718/2007, de 26 de noviembre, que resuelve sobre las mismas materias que las sentencias roles $\mathrm{N}^{\circ} 759$ y No 773 , se pronunció respecto de la posibilidad de imponer tributos sobre el patrimonio ("impuesto territorial" sobre inmuebles), y a partir de ello y de las exenciones involucradas, se hizo referencia a los problemas de igualdad (material) y capacidad económica, aunque finalmente el Tribunal Constitucional eludió un pronunciamiento sustancial acerca de dichas categorías, al resolver sobre la base de cuestiones formales.

Esta causa se originó en la impugnación de constitucionalidad de una reforma de la ley del impuesto territorial, por la que se establecían nuevos requisitos para mantener su exención, y que implicaba que contribuyentes que hasta entonces se encontraban exentos pudieran dejar de gozar de dicho beneficio. Para el recurrente este gravamen presenta la naturaleza de un impuesto sobre el patrimonio (lo llama impuesto "sobre el capital") y por ello puede estar siendo exigido a personas que carecen de capacidad de pago ("como serían los jubilados, enfermos, discapacitados o cesantes"). El recurrente agregó que la idea de capacidad de pago es exigida en la Constitución en el artículo 19 № 20 inciso $2^{\circ}$. 
El Tribunal desestimó el recurso, negando el carácter desproporcionado e injusto del tributo aludido. Afirmó que justicia tributaria constituye una cuestión valórica, reproduciendo los conceptos de las senbtencias roles $\mathrm{N}^{\circ}$ 203 (consid. $7^{\circ}$ ) y No $^{\circ} 219$ (consid. $8^{\circ}$ ). El Tribunal mencionó la capacidad de pago sólo en el contexto de situar la proporción que es posible exigir por impuestos en relación a la riqueza manifestada por el hecho gravado (renta, consumo o patrimonio) y a objeto de verificar el cumplimiento por parte del legislador del principio de prohibición de confiscatoriedad (considerandos $41^{\circ}$ al $43^{\circ}$ ).

Pero el Tribunal Constitucional alude a razones procesales la necesaria desestimación del recurso. Argumentó que, de acuerdo a la Constitución, la acción de inconstitucionalidad sólo cabe a objeto de impugnar leyes en cuanto resulten inconstitucionales en casos concretos, y que ello no fue probado por la recurrente (i.e., que en el caso concreto y no en abstracto la ley atenta contra una norma constitucional). Al sentenciador le pareció que el recurrente se encontraba impugnando una norma legal por no ajustarse de modo general y abstracto a la Constitución. Además de ello, el Tribunal decidió que la manifiesta falta de proporcionalidad y justicia del tributo debía ser examinada caso a caso, y por ello el recurrente también debió haber probado que en el caso concreto la ley vulneraba dicha limitación constitucional, lo que tampoco el recurrente hizo (consid. 44 y 45 ).

La sentencia rol No 1452/2010, de 5 de agosto, se pronunció sobre una solicitud de declaración de inconstitucionalidad de una norma legal que eliminaba un beneficio tributario. La sentencia afirmó (considerandos $19^{\circ} \mathrm{y}$ $\left.20^{\circ}\right)$ que el fundamento normativo de los beneficios tributarios se encuentra en la Constitución (artículo 65 inciso $4^{\circ} \mathrm{N}^{\circ} 1$ ), que su establecimiento forma parte de la potestad tributaria del Estado y de la amplia discrecionalidad de configuración del sistema tributario de que goza el legislador, orientado por consideraciones de política fiscal que estime en cada momento histórico, y que quiebran el principio de capacidad económica ínsito en los impuestos por razones objetivas legítimas de carácter económico, social o político, pero nunca en función de privilegios de carácter personal ${ }^{20}$.

El Tribunal desestimó la presentación del contribuyente sobre la base de que la potestad tributaria en el ámbito de ejercicio del legislador, tanto la

${ }^{20}$ Desde la sentencia rol No $280 / 1998$, el tribunal estimó como posible que la autoridad política hiciera uso de los tributos para orientar y dirigir la política económica: " $15^{\circ}[. .$.$] cabe recordar que el sistema constitucional chileno autoriza el cobro de impuestos$ para que el Estado con su producido pueda satisfacer las necesidades comunes a que está obligado por la Constitución. Es por ello que representa el medio que genera ingresos para cubrir el gasto público y además lo emplea la autoridad como un elemento para orientar y dirigir su politica económica". 
concesión como la eventual derogación de beneficios tributarios se sujetan al test de constitucionalidad que controla la razonabilidad del beneficio, atendida su idoneidad en función de las finalidades que se persiguen con su concesión o derogación, debido al impacto que provoca en el principio de tributación conforme a la capacidad impositiva de los contribuyentes como manifestación de la igualdad en el ámbito tributario definida en términos de que "a igual riqueza corresponde igual tributación" (consid. $21^{\circ}$ ). El Trribunal efectúa una distinción entre capacidad económica y capacidad contributiva, entendiendo que la segunda considera los fines extra-fiscales del tributo: " $21^{\circ}$ [...] Esta igualdad en cuanto a la capacidad económica ha sido complementada, hoy en dia, por la capacidad contributiva, que supone que por medio de la aplicación de ciertos tributos (o de los correspondientes beneficios y franquicias), el Estado se encuentra en condiciones de alentar o desalentar ciertas actividades en forma acorde con la obtención de los fines politicos, económicos y sociales que lo animan, los que, naturalmente, deben propender al logro del bien común".

El Tribunal defiende que el beneficio tributario suprimido tuvo un fin legítimo justificado por un momento histórico, el legislador no está obligado a mantenerlo de modo permanente menos aún cuando han cambiado los escenarios que lo originaron, pues debe revisar la política fiscal conforme a las exigencias del bien común (considerandos $22^{\circ}$ a $25^{\circ}$ ).

Finalmente, también existe una referencia a los principios constitucionales tributarios en el voto disidente de la senbtencia roles acumulados $\mathrm{N}^{\circ}$ $1399 / 1469$, de 4 de noviembre de 2010, referido a asuntos equivalentes al caso "Gerhard Schweinitz con SII".

Los magistrados disidentes defendieron la existencia de un amplio ámbito de discrecionalidad del legislador en la determinación de los tributos, la configuración del sistema tributario y del establecimiento de categorías de contribuyentes en razón de criterios usualmente aceptados (tales como la capacidad económica). Ello le permite perseguir tanto fines recaudatorios como extra-recaudatorios, de promoción del bien común, de política económica destinada a motivar o desincentivar el desarrollo de una actividad, a corregir distorsiones en el mercado, estabilizar la economía, redistribuir ingresos, etc. (sentencias roles $\mathrm{N}^{\circ} 1295 / 2008$ y No 1034/2008). Agregan que, conforme a la igualdad en materia tributaria, es "de la esencia" que se establezcan regímenes tributarios diferenciados atendiendo a las capacidades contributivas de los contribuyentes o cargas tributarias semejantes en caso de capacidades contributivas iguales (apartado $14^{\circ}$ ).

En tal perspectiva, el legislador es libre para agrupar contribuyentes, estableciendo categorías, que se encuentran en situaciones análogas, o para formular distingos, y también es libre de modificar dichas categorías conforme a razones de mérito que considere oportunas, siendo la capacidad 
contributiva un criterio de diferenciación o agrupamiento, entre otros, junto al origen de las rentas, el beneficio del contribuyente, u otro parámetro que estime conveniente (apartado 26).

En una apretada síntesis, suficiente para los fines del presente trabajo, podemos sostener que, en relación a la capacidad económica, el Tribunal Constitucional de Chile la ha entendido inicialmente como uno de los criterios que el legislador puede usar para efectos de crear categorías de contribuyentes a la hora de establecer los tributos y que, en cuanto obedezca a criterios objetivos, el establecimiento de categorías de contribuyentes se adecua al principio de igualdad. Esta concepción de capacidad económica comparte espacio con otros criterios de reparto de la carga impositiva, tales como el origen de las rentas, el beneficio del contribuyente, u otro parámetro que el legislador estime conveniente. Finalmente, sostiene que el legislador goza de un muy amplio margen de discrecionalidad en el ejercicio de su potestad de configuración del sistema tributario, que le permite perseguir tanto fines recaudatorios como extra-recaudatorios, de promoción del bien común, y le permite hacer uso de los tributos como una herramienta para lograr fines de carácter político, económico y social. Con todo, ello se encuentra mediado por una serie de condiciones dada la gravedad que implica afectar el principio de capacidad contributiva. Existe una progresiva mutación en la comprensión de la categoría de la capacidad económica desde un criterio de caracter económico a un principio jurídico implicado en la Constitución a través del principio de igualdad constitucional. En efecto, el Tribunal Constitucional ha sostenido que la tributación conforme a la capacidad impositiva de los contribuyentes es manifestación de la igualdad en el ámbito tributario definida en términos de que "a igual riqueza corresponde igual tributación".

\section{Jurisprudencia española.}

Sobre los principios que enmarcan el ejercicio del poder tributario y sobre el contenido que ha de darse al principio de capacidad económica el Tribunal Constitucional de España se pronunció poco después de aprobada la Constitución en la sentencia $N^{\circ} 27 / 1981$, de 20 de julio. En ella se trató la posible inconstitucionalidad de la regulación que una ley de presupuestos hacía en materia tributaria, lo que los recurrentes estimaban contrario a los artículos 31.1 y 134.7 CPol.Esp. ${ }^{21}$.

En el fundamento jurídico $4^{\circ}$, el Tribunal establece que en el ejercicio del poder tributario "[...] no cabe omitir, en tal supuesto y menos cuando se tratara de una verdadera modificación, los imperativos del articulo 31.1 de la

${ }^{21} \mathrm{El}$ artículo 134.7 CPol.Esp. establece: "La ley de presupuestos no puede crear tributos. Podrá modificarlos cuando una ley tributaria sustantiva asi lo prevea". 
Constitución, que, al obligar a todos a contribuir al sostenimiento de los gastos públicos, ciñe esta obligación en unas fronteras precisas: la de la capacidad económica de cada uno y la del establecimiento, conservación y mejora de un sistema tributario justo e inspirado en los principios de igualdad y progresividad". Considera el Tribunal que la Constitución española, a diferencia de otras (como es el caso, como se ha visto, de la chilena), alude expresamente al principio de capacidad contributiva. No obstante, el principio de justicia, piedra angular del ordenamiento jurídico, en materia tributaria no se agota en el cumplimiento del principio de capacidad económica.

Cumplir con el citado principio implica para el legislador una exigencia lógica de buscar la riqueza allí donde la riqueza se encuentra. Pero ello no asegura por sí sólo el principio de justicia tributaria sino que no ha de separarse el sistema tributario de los principios de igualdad y progresividad. Se desprende de la sentencia que el criterio de distribución de los gastos públicos basado en el principio de capacidad económica requiere, según el precepto constitucional, que se haga conforme a un principio de igualdad material. Se han de establecer diferencias entre las personas obligadas a contribuir de acuerdo con el criterio que implica la progresividad a la hora de hacer frente a las cargas públicas.

En la sentencia $\mathrm{N}^{\circ} 150 / 1990$, de 4 de octubre, el Tribunal trató un recurso en el que se alegaba la inconstitucionalidad de un recargo sobre el impuesto sobre la renta de las personas físicas que establecía la Comunidad Autónoma de Madrid. Entre los diversos alegatos planteados por los recurrentes figuraba el carácter confiscatorio de esa figura tributaria pues implica un aumento de gravamen sobre la renta que ya estaba siendo gravada por el Estado. Sobre esta alegación consideró el Tribunal en el fundamento jurídico $9^{\circ}$ que el principio de no confiscatoriedad del artículo 31.1 era de difícil concreción. No obstante añadió a las consideraciones de la sentencia $\mathrm{N}^{\circ} 27 / 1981$ que: "[...] la probibición de confiscatoriedad supone incorporar otra exigencia lógica que obliga a no agotar la riqueza imponible sustrato, base o exigencia de toda Imposición so pretexto del deber de contribuir; de ahi que el límite máximo de la imposición venga cifrado constitucionalmente en la probibición de su alcance confiscatorio".

Volvió a tener ocasión el Tribunal de tratar el principio de capacidad económica en la sentencia $\mathrm{N}^{\circ} 221 / 1992$, de 11 de diciembre. En ella se tratan cuestiones de inconstitucionalidad relacionadas con la regulación del impuesto municipal sobre el incremento del valor de los terrenos, fundamentadas, entre otras cosas, en su contradicción con el principio de capacidad económica. Sobre esto, en el fundamento jurídico $4^{\circ}$ el Tribunal recoge y reitera lo dicho en las sentencias anteriores, recuerda que el principio vincula tanto a particulares como a los poderes públicos (sentencia 
$\mathrm{N}^{\circ} 76 / 1990$, de 26 de abril) y añade que: "Ello no significa, sin embargo, que la capacidad contributiva pueda erigirse en criterio exclusivo de justicia tributaria, en la única medida de la justicia de los tributos. Como ya indicó este Tribunal en la citada STC 27/1981, la Constitución alude expresamente al principio de capacidad económica, pero lo hace sin agotar en ella el principio de justicia en materia tributaria. Es por tanto constitucionalmente admisible que el legislador establezca impuestos que, sin desconocer o contradecir el principio de capacidad económica, estén orientados al cumplimiento de fines o a la satisfacción de intereses públicos que la Constitución preconiza o garantiza; y basta que dicha capacidad económica exista, como riqueza o renta real o potencial en la generalidad de los supuestos contemplados por el legislador al crear el impuesto, para que aquel principio constitucional quede a salvo (STC 37/1987, fundamento jurídico 13). El principio de capacidad económica opera, por tanto, como un limite al poder legislativo en materia tributaria. Aunque la libertad de configuración del legislador deberá en todo caso, respetar los limites que derivan de dicho principio constitucional, que quebraria en aquellos supuestos en los que la capacidad económica gravada por el tributo sea no ya potencial sino inexistente o ficticia".

Esta sentencia introduce un matiz a la efectividad del principio de capacidad económica en cuanto a criterio para la distribución de la carga tributaria. Reconoce el tribunal que el principio se respetará si la capacidad es real o potencial aunque el legislador persiga con el tributo atender a otro tipo de fines de interés público que prevea la Constitución. Abre con ello una posibilidad al poder tributario de establecer en el sistema tributario figuras o medidas que no se incorporan en el sistema para distribuir las cargas públicas sino con finalidades diferentes ya que, de acuerdo con el fundamento jurídico $5^{\circ}$ de la sentencia $\mathrm{N}^{\circ}$ 221/1992: "[...] el principio de capacidad económica no es un axioma del que puedan extraerse, por simple deducción lógica, consecuencias positivas, precisas y concretas, sobre la particular regulación de cada figura tributaria. De otra, es constitucionalmente posible que el legislador tributario, al regular cada figura impositiva, otorgue preeminencia a otros valores o principios, respetando, en todo caso, los límites establecidos por la Constitución". En la misma línea se encuentra la sentencia $\mathrm{N}^{\circ}$ 134/1996, de 22 de julio, en cuyo fundamento jurídico $8^{\circ}$ el Tribunal expone, que se puede exceptuar el principio de capacidad económica mediante exenciones por dos motivos: primero, por responder a otros principios que resulten amparados por la Constitución y, segundo, por hacer efectivo el propio principio de capacidad económica.

Con las sentencias $\mathrm{N}^{\circ} 221 / 1992$ y $\mathrm{N}^{\circ} 134 / 1996$ el Tribunal Constitucional abrió una línea de flexibilización al principio de capacidad económica. El establecimiento de los tributos por parte del legislador no ha de atenerse 
exclusivamente al citado principio puesto que no monopoliza la justicia tributaria. El sistema tributario bien puede incorporar figuras que atiendan a otros valores o principios también reconocidos en la Constitución. El gravamen no necesariamente ha de estar establecido en función de la capacidad económica si el legislador ha tenido en cuenta otras circunstancias amparadas en la norma fundamental.

La extrafiscalidad no es el único factor que puede asociarse con la flexibilización de los rigores del principio de capacidad económica. Como ya se dijo, el deber de contribuir a los gastos públicos se realiza a través de un sistema tributario referenciado en el principio de justicia. Se puede interpretar que el legislador constitucional vinculaba a todos y cada uno de los tributos que pueden ser incorporados al sistema. Sin embargo, en la sentencia $\mathrm{N}^{\circ}$ 182/1997, de 28 de octubre, en la que se trataba la constitucionalidad de un decreto-ley que regulaba aspectos del impuesto sobre la renta de las personas físicas, el Tribunal matizó esta idea. En el fundamento jurídico $7^{\circ}$ expresó que el principio de capacidad económica no está referido a cada figura tributaria en particular sino al conjunto del sistema tributario ${ }^{22}$.

Dentro de ese sistema, sin embargo, el Tribunal ha discriminado entre tributos que responden al citado principio y tributos en los que el principio no tiene tanto peso. La sentencia $\mathrm{N}^{\circ} 189 / 2005$, de 7 de julio, también trató la adecuación de un decreto-ley como norma con la que regular aspectos tributarios. Traído aquí el fallo de forma sumaria, se ve que el Tribunal entiende que la citada norma no puede afectar al deber de contribuir a los

${ }^{22}$ Dice el Tribunal Constitucional de España en el fundamento jurídico 7: “De lo anterior se infiere que el Decreto-ley no puede alterar ni el régimen general ni los elementos esenciales del deber de contribuir, lo que exige precisar a los meros efectos de resolver la constitucionalidad del artículo 2 del Real Decreto-ley 5/1992 impugnado cómo se encuentra definido dicho deber en la Norma fundamental, concretamente en su articulo 31.1;y es que, como señalamos en la STC 111/1983, comprobar cuándo el Decreto-ley 'afecta' a un derecho, deber o libertad 'exige también que se tenga muy en cuenta la configuración constitucional del derecho -en este caso, deber-afectado en cada caso'. 8. A este respecto, avanzando en las consideraciones que sobre el deber de contribuir a los gastos públicos ha realizado el Tribunal en otros pronunciamientos (SSTC 27/1981, 110/1984, 126/1987, 45/1989, 76/1990, 150/1990, 197/1992, 221/1992, 134/1996, 173/1996 y 38/1997), la Constitución conecta el citado deber con el criterio de la capacidad económica (con el contenido que a este principio de justicia material se ha dado, fundamentalmente, en las SSTC 27/1981, 37/1987, 150/1990, 221/1992 y 134/1996), y lo relaciona, a su vez, claramente, no con cualquier figura tributaria en particular, sino con el conjunto del sistema tributario. El artículo 31.1 C.E., en efecto, dijimos tempranamente en la STC 27/1981, «al obligar a todos al sostenimiento de los gastos públicos, ciñe esta obligación en unas fronteras precisas: La de la capacidad económica de cada uno y la del establecimiento, conservación y mejora de un sistema tributario justo inspirado en los principios de igualdady progresividad» (fundamento juridico $4^{\circ}$ )". 
gastos públicos lo que no puede ser interpretado como un óbice a que se regule mediante esa norma fundamentada en la extraordinaria y urgente necesidad la materia tributaria. Esta afectación se produce cuando el Decretoley introduce modificaciones en el régimen del impuesto sobre la renta de las personas físicas a través del cual, como dice en el fundamento jurídico $8^{\circ}$ el Tribunal: "[...] se realiza la personalización del reparto de la carga fiscal en el sistema tributario según los criterios de capacidad económica, igualdad y progresividad, lo que lo convierte en una figura impositiva primordial para conseguir que nuestro sistema tributario cumpla los principios de justicia tributaria que impone el articulo 31.1 CE, dada su estructura y hecho imponible (STC 134/1996)". Prosigue el juzgador diciendo que el impuesto citado es la figura central de la imposición directa en la que pueden manifestarse con mayor claridad los principios de capacidad económica, igualdad y progresividad, además de hacer posible la redistribución de la renta y la solidaridad que caracterizan el Estado social y democrático de Derecho.

No sucede lo mismo con otros tributos, como es el caso del Impuesto sobre sucesiones y donaciones que grava las transmisiones lucrativas mortis causa. Según establece el supremo intérprete de la Constitución en el fundamento jurídico $8^{\circ}$ de la sentencia $N^{\circ} 189 / 2005$ no siendo un tributo global sobre la renta o sobre el consumo y estando limitado a gravar una concreta manifestación de capacidad económica, la modificación de su régimen jurídico por un Decreto-ley no altera el deber de contribuir de acuerdo con la capacidad económica del contribuyente. Iguales reflexiones se aportan en la sentencia $\mathrm{N}^{\circ} 108 / 2004$, de 30 de junio, en la que tampoco tienen peso específico en cuanto a hacer efectivo el principio de capacidad económica dentro del sistema tributario la imposición sobre bebidas alcohólicas dado su carácter marginal en el sistema.

Profundizando en esta línea de interpretación es más rotundo el Tribunal en el Auto $\mathrm{N}^{\circ} 71 / 2008$, de 26 de febrero, cuando expone en el fundamento jurídico $5^{\circ}$ “[...] aun cuando el principio de capacidad económica implica que cualquier tributo debe gravar un presupuesto de becho revelador de riqueza, la concreta exigencia de que la carga tributaria se module en la medida de dicha capacidad sólo resulta predicable del 'sistema tributario' en su conjunto, de manera que puede afirmarse, trasladando mutatis mutandis nuestra doctrina acerca de cuándo un Decreto-Ley afecta al deber de contribuir, que sólo cabe exigir que la carga tributaria de cada contribuyente varie en función de la intensidad en la realización del hecho imponible en aquellos tributos que por su naturaleza y caracteres resulten determinantes en la concreción del deber de contribuir al sostenimiento de los gastos públicos que establece el artículo 31.1 CE. Éste es, como hemos tenido ocasión de afirmar varias veces, el caso del impuesto sobre la renta de las personas físicas [...]. Pero, claramente, no es 
el caso de la llamada 'tasa' del juego, tributo que, ni tiene carácter general (esto es, no grava la renta global de las personas físicas o jurídicas, sino una especifica manifestación de capacidad económica: por lo que aquíinteresa, los rendimientos que se obtienen con la explotación de las máquinas recreativas tipo B), ni, por sus características, puede afirmarse que constituya uno de los pilares básicos o estructurales de nuestro sistema tributario, ni, en fin, por su estructura y su hecho imponible puede considerarse como instrumento idóneo para alcanzar los objetivos constitucionales a que hemos aludido".

Una tercera línea jurisprudencial que flexibiliza el principio de capacidad económica junto con la extrafiscalidad o la idea de sistema tributario que se han comentado. La sentencia $\mathrm{N}^{\circ} 33 / 2006$, de 13 de febrero, en su fundamento jurídico $4^{\circ}$ aproxima que la neutralización del nacimiento de la obligación tributaria derivada de la realización de un hecho imponible que supone la capacidad económica de la persona contribuyente será constitucionalmente válido "[...] cuando responda a fines de interés general que la justifiquen (por ejemplo, por motivos de politica económica o social,para atender al minimo de subsistencia, por razones de técnica tributaria, etc.) quedando, en caso contrario, proscrita [...]". El Tribunal añade, pues, un criterio más para la flexibilización del deber de contribuir conforme a la capacidad económica, pues menciona la política económica o la técnica tributaria como motivos válidos de excepción.

De las diferentes sentencias aquí expuestas se extrae que el Tribunal Constitucional español ha seguido una línea de flexibilización de los rigores que implica el principio de capacidad económica previsto en el artículo 31.1 CPol. Esp. Comenzó identificándolo con la necesidad de gravar riqueza real o virtual para seguir atribuyéndole la característica de límite al poder tributario en tanto que no puede agotarse la riqueza que grava. Se ha cuidado también de exponer que no se trata del único principio sobre el que basar la justicia del sistema tributario pues ha de seguirse en función de los principios de igualdad y progresividad. En esa línea de delimitación del principio de capacidad también se ha establecido una línea de flexibilización del principio que se materializa en la utilización extrafiscal del poder tributario, el hecho de que las figuras tributarias no responden con igual rigor al principio $y$, finalmente, la posibilidad de exceptuarlo si se dan motivos de política económica o técnica tributaria válidos.

\section{REFLEXIÓN FINAL}

En las líneas anteriores se han recopilado diferentes pronunciamientos de tribunales sobre el deber de contribuir y el principio de reparto de la carga tributaria en dos sistemas jurídicos distintos: chileno y español. En 
este estudio de Derecho comparado se ha pretendido analizar una hipótesis de partida como es que, a pesar de las diferencias que incialmente pueden advertirse sobre la regulación de estos temas, ambos ordenamientos jurídicos se van decantando hacia posiciones similares.

El constituyente chileno ha previsto en el artículo 19 No 20 CPol. un amplio marco dentro del que puede ejercerse el poder tributario. El principio de igualdad para contribuir a los gastos públicos es el criterio de distribución pero, especifica la jurisprudencia, no ha de ser sólo una igualdad formal sino que debe incluir elementos materiales (varios, v.g., la no confiscatoriedad). El criterio para esa igualdad lo fijará el legislador entre los varios existentes en la doctrina económica: capacidad económica, origen de rentas, beneficio del contribuyente y otros. No obstante, se considera que es esencia de la norma tributaria gravar de acuerdo con la capacidad económica.

La importancia que le concede el Tribunal Constitucional a la capacidad económica es progresiva.

La vinculación del principio constitucional de igualdad con el criterio económico de la capacidad económica se ha ido tornando cada vez más complejo, derivando incluso en una comprensión de esta última categoría como un principio jurídico. En efecto, el avance de consideraciones de bien común como fines constitucionalmente lícitos de política fiscal conducen a ponderarlas con los asentados criterios tributarios. De dicha ponderación ha surguido la reflexión en orden a que la búsqueda de fines de carácter político, económico y social mediante los tributos no puede, sin más, quebrar el principio de tributación conforme a la capacidad económica. Ello conduce a evidenciar una paulatina mutación en la comprensión de la categoría de la capacidad económica desde un criterio de caracter económico a un principio juridico implicado en la Constitución, inserto en el principio de igualdad constitucional. En efecto, el Tribunal Constitucional de Chile ha sostenido que la tributación conforme a la capacidad impositiva de los contribuyentes es manifestación de la igualdad en el ámbito tributario definida en términos de que "a igual riqueza corresponde igual tributación".

Es admisible la crítica de que no hay una línea jurisprudencial consolidada acerca de la preponderancia del principio de capacidad económica sobre otros principios de distribución de la carga tributaria a la hora de hacer efectivo el principio de igualdad material en el ámbito tributario. Sí, en cambio, puede entenderse como una idea de la orientación que puede seguir el legislador chileno a la hora de establecer tributos, pues con ello responde a una idea de justicia.

Por su parte, el legislador constitucional español establece expresamente que el principio de justicia en el sistema tributario se hace efectivo si se contribuye de acuerdo con la capacidad económica que da contenido al 
principio de igualdad y se entiende de acuerdo con un principio de progresividad. No son los mismos márgenes que se dan al legislador chileno, pues se cita expresamente un modo de reparto de la carga tributaria. Sin embargo, es la jurisprudencia la que, posteriormente, va ampliando los márgenes de actuación relativizando la importancia del principio mediante la admisión de la extrafiscalidad de forma que los tributos puedan responder a otros fundamentos constitucionales, el concepto de sistema tributario que permite circunscribir a ciertos tributos -considerados claves- los rigores del principio y las excepciones a su realización por motivos de política económica o técnica tributaria.

De acuerdo con lo anterior puede confirmarse la hipótesis con la que comenzaban estas líneas en los siguientes términos. Dos sistemas tributarios diferentes y distantes en sus planteamientos en cuanto al rigor de sus fundamentos constitucionales hacia el poder tributario, llegan a un punto de acercamiento en cuanto a los criterios de distribución de las cargas tributarias. El chileno desde la amplitud de los márgenes de actuación dibuja una, siquiera tímida, tendencia hacia el principio de capacidad económica mientras que el español va desde una decidida apuesta por el principio hacia su flexibilización. Estas dos tendencias - una hacia la concreacción de límites y otra hacia la relativización de los existentes- en principio contrarias bien pueden tener un punto de encuentro en su desarrollo si coincide en que el principio de capacidad económica es el contenido del principio de igualdad material en el ámbito tributario, si bien no es el único en el que el legislador fundamenta el ejercicio del poder tributario.

En ambos casos también se pone de manifiesto algo que no carece de importancia, aunque pueda resultar obvio, como es el papel que juega la jurisprudencia en la evolución de un sistema jurídico, el cual puede partir de unos determinados fundamentos y, por mor de la labor de jueces e intérpretes, evoluciona hacia planteamientos que pudiera entenderse alejados de los criterios o interpretaciones iniciales. No se entienda esta última idea como una crítica negativa hacia la actuación de los jueces favorable al inmovilismo jurídico. Este fenómeno es una cuestión natural en cualquier ordenamiento jurídico que trata de adaptarse a una realidad que, en el caso de la económica íntimamente relacionada con lo tributario, es altamente dinámica.

\section{Bibliografía}

\section{Literatura}

Figueroa VAldés, Juan, Las Garantías Constitucionales del Contribuyente en la CPR de 1980, Editorial Jurídica de Chile, Santiago, 1985

MASBernat, Patricio, Un análisis crítico de la doctrina relativa a los principios materiales de la tributación en Chile, EN VV.AA., Problemas actuales de Derecho Tributario 
comparado, Una perspectiva de Iberoamérica, Editorial Librotecnia, Santiago de Chile, en prensa.

Masbernat, Patricio, Principios constitucionales tributarios en la sentencia, Roles No1399-09-INA y No 1469-09-INA, acumulados, del Tribunal Constitucional, de 4 de noviembre de 2010. Referencia al caso 'Gerhard Schweinitz con SII, Corte de Apelaciones de Concepción, Rol 800-2010, de 1 de diciembre de 2010, En Estudios Constitucionales, CECOCH, Santiago de Chile, 2011, No2, en prensa.

\section{JURISPRUDENCIA}

a) Cortes de Apelaciones y Corte Suprema

Corte de Apelaciones de Santiago, 26 de marzo de 2011, Rol: 5802-2010, reclamo de ilegalidad en ámbito municipal, "Sociedad de Inversiones Madel Limitada c. I. Municipalidad de Providencia”. Cita de Base de Datos www.westlaw.cl: CL/ JUR/3541/2011 [visita 17 de julio de 2011].

Corte de Apelaciones de Concepción, 1 de diciembre de 2010, Rol 800-2010, reclamación tributaria, "Gerhard Schweinitz Gutiérrez c. Servicio de Impuestos Internos", Cita Base de Datos www.westlaw.cl: CL/JUR/10301/2010 (visita, 3 de agosto de 2011).

Corte Suprema, 16 de octubre de 1996, rol 374-96, recurso de inaplicabilidad por inconstitucionalidad, "American Express Bank con Servicio de Impuestos Internos", Gaceta Jurídica No197, 1996, p. 202-207.

Corte Suprema, 2 de septiembre de 1997, rol 3983-1996, Recurso de Casación en la Forma, "Servicio de Impuestos Internos con Juan Pablo Benjamín Dávila Silva", C. $17^{\circ}$. Base de Datos Legal Publishing, www.legalpublishing.cl, archivo $\mathrm{N}^{\circ} 14796$ [Visita 10 de marzo de 2011]. .

Corte Suprema, 11 de mayo de 1994, Rol No 19584-1994, recurso de inaplicabilidad por inconstitucional, "Sociedad Comercial Ivonne S. A. contra Tribunal Tributario de la Duodécima Región”, Cita de Base de datos Westlaw Chile, www.westlaw.cl: CL/JUR/31/1994 [Visita 10 de agosto de 2011].

Corte Suprema, 28 de enero de 1992, Rol 16.293, recurso de inaplicabilidad por inconstitucionalidad interpuesto en contra de disposiciones de la Ley de Rentas Municipales, "Compañía de Teléfonos de Chile contra Municipalidad de Villa Alemana". Cita de Base de Datos Microjuris www.microjuris.cl: MJCH_MJJ1522 / RDJ1522 [fecha de visita agosto 7, 2010].

b) Tribunal Constitucional de Chile [Disponible en www.tribunalconstitucional.cl] Sentencia rol No 203 de 6 de diciembre de 1994.

Sentencia rol No 219 de 10 de julio de 1995.

Sentencia rol No 280 de 20 de octubre de 1998.

Sentencia rol No 718, de 26 de noviembre de 2007.

Sentencia rol No1452, de 5 de agosto 2010.

Sentencia roles acumulados No1399/1469, de 4 de noviembre de 2010.

c) Tribunal Constitucional de España [Disponible en www.tribunalconstitucional.es] Auto $\mathrm{N}^{\circ} 71 / 2008$ de 26 de febrero

Sentencia No 27/1981, de 20 de julio.

Sentencia No 33/2006, de 13 de febrero

Sentencia No 37/1987, de 14 de abril.

Sentencia No $76 / 1990$ de 26 de abril 
Sentencia No 108/2004, de 30 de junio

Sentencia No 134/1996, de 22 de julio.

Sentencia No 150/1990, 4 de octubre.

Sentencia No 221/1992, de 11 de diciembre.

Sentencia No 182/1997, de 28 de octubre.

Sentencia No 189/2005, de 7 de julio. 
